\section{Buchrezension zu: The Hidden Beauty of the Microscopic World}

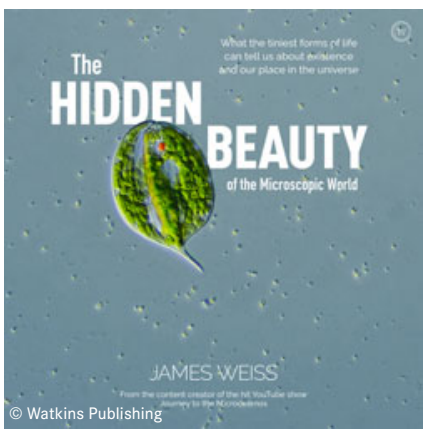

The Hidden Beauty of the Microscopic World

What the tiniest forms of life

can tell us about existence and our place in the universe James Weiss

256 S., Watkins Publishing, 2021. SC nur in den USA erhältlich.

ISBN: 9781786784490

Auch als E-Book erhältlich

DOI: 10.1007/s12268-022-1694-9

(C) Der Autor 2022

James Weiss ist der Naturfotograf der mikroskopischen Lebenswelten. Seine Korallenriffe sind die Bewüchse auf Aquarienscheiben, sein Dschungel der Schlamm einer Pfütze und seine Savanne eine Handvoll Waldboden. „The Hidden Beauty of the Microscopic World" dokumentiert in bestechenden Bildern das vielfältige Leben, das dem unbewaffneten Auge verborgen bleibt. James Weiss nimmt uns mit auf eine faszinierende Reise in die oft noch unerforschte und wundersame Welt der Mikroorganismen.

Beim Lesen des Buchs wird sofort deutlich, mit welchem Enthusiasmus der Autor etliche Stunden am Mikroskop verbracht hat. Zeit, die sich in der Qualität seiner Aufnahmen widerspiegelt.

Begleitet von schönen Fotos und in einer leicht zugänglichen Sprache stellt uns James Weiss auf unterhaltsame Art und Weise typische, aber auch exotische Vertreter unterschiedlichster Gruppen von Mikroorganismen vor. Die liebevolle Art, in der er seine Untersuchungsobjekte be- schreibt, wirkt an einigen Stellen vielleicht etwas übertrieben, ist aber auch Ausdruck der Begeisterung des Autors für seine „Haustierchen“. Bisweilen verliert sich hierdurch jedoch auch etwas der sachbezogene Fokus. Eingebettet in den sehr schön bebilderten Blick in die Welt der Mikroorganismen teilt James Weiss mit uns seine Geschichte, die ihn zu einem begeisterten Beobachter des Mikrokosmos gemacht hat, was sein Werk zu einem sehr persönlichen Buch macht.

Wenn auch klein im Format, ist das Buch ein Bildband mit zum Teil beeindruckenden Aufnahmen des mikroskopischen Lebens, das uns überall umgibt. „The Hidden Beauty of the Microscopic World" ist jedoch kein systematischer Naturführer und auch nicht als Bestimmungsbuch für das Leben im Wassertropfen geeignet. Wer nach der Lektüre des Buchs die Wunderwelt der Mikroorganismen eigenständig entdecken möchte, hätte sicher ein kurzes Kapitel mit Tipps zur Auswahl eines ersten Mikroskops geschätzt. Viele der gezeigten Fotos würden auch sehr von einem Druck auf Hochglanzpapier profitieren, was die Kosten für das Buch jedoch sicher deutlich erhöht und es so gerade für junge Leser:innen weniger attraktiv gemacht hätte.

Das Buch ist ein perfekter Begleiter zu den Youtube Kanälen „Jam's Germs“ und „Journey to the Microcosmos" - von James Weiss. Viele der im Buch gezeigten Aufnahmen können hier zum Leben erweckt werden.

Wer einen ersten unkomplizierten, dennoch recht aufschlussreichen und unterhaltsamen Einblick in die Welt der Mikroorganismen, ihre vielfältigen Formen und Lebensweisen sucht, der wird an „The Hidden Beauty of the Microscopic World" viel Gefallen finden.

\section{Jan Pané-Farré, \\ Philipps-Universität Marburg, jan.panefarre@chemie.uni- marburg.de}

Diese Rezension erscheint Open Access.

$$
\begin{aligned}
& \text { * Funding note: Open Access funding } \\
& \text { enabled and organized by Projekt DEAL. } \\
& \text { Open Access: Dieser Artikel wird unter } \\
& \text { der Creative Commons Namensnen- } \\
& \text { nung } 4.0 \text { International Lizenz veröffent- } \\
& \text { licht, welche die Nutzung, Vervielfälti- } \\
& \text { gung, Bearbeitung, Verbreitung und } \\
& \text { Wiedergabe in jeglichem Medium und } \\
& \text { Format erlaubt, sofern Sie den/die ur- } \\
& \text { sprünglichen Autor(en) und die Quelle } \\
& \text { ordnungsgemäß nennen, einen Link zur } \\
& \text { Creative Commons Lizenz beifügen und } \\
& \text { angeben, ob Änderungen vorgenommen } \\
& \text { wurden. Die in diesem Artikel enthalte- } \\
& \text { nen Bilder und sonstiges Drittmaterial } \\
& \text { unterliegen ebenfalls der genannten } \\
& \text { Creative Commons Lizenz, sofern sich } \\
& \text { aus der Abbildungslegende nichts ande- } \\
& \text { res ergibt. Sofern das betreffende Mate- } \\
& \text { rial nicht unter der genannten Creative } \\
& \text { Commons Lizenz steht und die betref- } \\
& \text { fende Handlung nicht nach gesetzlichen } \\
& \text { Vorschriften erlaubt ist, ist für die oben } \\
& \text { aufgeführten Weiterverwendungen des } \\
& \text { Materials die Einwilligung des jeweiligen } \\
& \text { Rechteinhabers einzuholen. Weitere De- } \\
& \text { tails zur Lizenz entnehmen Sie bitte der } \\
& \text { Lizenzinformation auf } \\
& \text { http://creativecommons.org/licenses / } \\
& \text { by/4.0/deed.de. }
\end{aligned}
$$

